\title{
Um relato de uma experiência de ensino de geometria usando mosaicos e o modelo de Van Hiele
}

\author{
A report of a geometry teaching experience using mosaics and the Van Hiele model
}

\author{
ANDRÉ VICTOR RIBEIRO DE CAMPOS ${ }^{\mathrm{a}}$ \\ ROGERIO LUIZ QUINTINO DE OLIVEIRA JUNIOR ${ }^{\mathrm{b}}$
}

\begin{abstract}
Resumo
Neste artigo, relatamos uma experiência vivida, em 2019, por um dos autores deste trabalho em sala de aula durante a elaboração de sua dissertação de mestrado. Nela, procurou-se ensinar, de forma lúdica, alguns conceitos e definições sobre triângulos e quadriláteros para estudantes do $7^{\circ}$ ano do Ensino Fundamental de uma escola municipal da cidade do Rio de Janeiro. Para este projeto, utilizou-se da arte dos mosaicos e do Modelo de níveis de aprendizado de geometria de Van Hiele como suporte teórico para a experiência. Os mesmos conteúdos de geometria foram ensinados em duas turmas do $7^{\circ}$ ano, uma da maneira tradicional, com explicação no quadro junto com o livro e a apostila da escola e, na outra, utilizou-se a arte dos mosaicos. Por último, esse trabalho aponta algumas vantagens na percepção geométrica e na aprendizagem dos alunos da turma que usou a interdisciplinaridade entre Matemática e Arte.
\end{abstract}

Palavras-chave: Ensino, Geometria, Mosaicos, Teoria de Van Hiele, Arte.

\begin{abstract}
In this article, we report an experience lived, in 2019, by one of the authors of this work in the classroom during the elaboration of his master's dissertation. In it, we tried to teach, in a playful way, some concepts and definitions about triangles and quadrilaterals for students in the 7th year of Elementary School of a municipal school in the city of Rio de Janeiro. For this project, the art of mosaics and the Model of levels of learning of geometry of Van Hiele were used as theoretical support for the experience. The same geometry content was taught in two 7th grade classes, one in the traditional way, with explanation on the board along with the schoolbook and handout, and in the other, the art of mosaics was used. Finally, this work points out some advantages in the geometric perception and in the learning of the students of the class that used the interdisciplinarity between Mathematics and Art.
\end{abstract}

Keywords: Teaching, Geometry, Mosaics, Van Hiele's theory, Art.

MSC2010: 97D10

\footnotetext{
${ }^{a}$ Rede Municipal do Rio de Janeiro, Rio de Janeiro, Brasil. E-mail: avrcampos@ @otmail.com

${ }^{\mathrm{b}}$ Universidade Estadual do Rio de Janeiro, Rio de Janeiro, Brasil; ORCID: 0000-0002-9894-9980. E-mail:

roger.quintino@hotmail.com
} 


\title{
1. Introdução
}

Ensinar Geometria no ciclo fundamental no Brasil se tornou um verdadeiro desafio, não só para os professores quanto para os estudantes, pois eles, em geral, não conseguem ter uma boa instrução, mesmo que básica, nesta disciplina. E isto também se deve ao fato da má formação do professor de matemática, apesar dos PCN enfatizarem a importância da Geometria na formação do aluno:

\begin{abstract}
Os Parâmetros Curriculares Nacionais propõem para o ensino da geometria, que o aluno desenvolva a compreensão do mundo em que vive, aprendendo a descrevê-lo, representá-lo e a se localizar nele, estimulando ainda a criança a observar, perceber semelhanças e diferenças, a identificar regularidades, compreender conceitos métricos, e permitir o estabelecimento de conexões entre a Matemática e outras áreas do conhecimento; porém este objetivo não está sendo realizado por diversas razões, tais como o tema geometria estar normalmente no final dos livros didáticos, a falta de preparo do professor em geometria, detectada após o movimento da Matemática Moderna no Brasil, onde a Álgebra é mais enfatizada. ([4], 2004, p. 1)
\end{abstract}

Existem vários trabalhos que abordam o porquê de o ensino de Geometria ter chegado a este ponto tão adverso para estudantes e professores, apesar de ser uma disciplina essencial, como vimos no texto dos PCN acima. Dentre eles, podemos citar [5] (1995), [6] (1993), [1] (1993), entre outros. No entanto, este artigo não pretende explorar essa parte histórica da Geometria, e sim mostrar uma proposta de ensino desta importante área da Matemática utilizando-se da Arte em uma experiência numa turma de $7^{\circ}$ ano do Ensino Fundamental de uma escola municipal da cidade do Rio de Janeiro realizada em 2019 como parte de uma dissertação de Mestrado elaborada por um dos autores deste trabalho, o qual será denominado, a partir de agora, de professor-autor.

Para utilizar a Arte como um meio facilitador do ensino-aprendizagem de Geometria em uma turma do $7^{\circ}$ ano, optou-se pela construção de mosaicos pelos alunos apoiados pelo Modelo de aprendizagem de Geometria de Van Hiele. Este experimento contou com 12 aulas de 50 minutos cada.

Mosaicos são muito usados no mundo desde a antiguidade e muito conhecidos pelos estudantes, como podemos ver, por exemplo, no calçadão da famosa praia de Copacabana, como ilustrado na Figura 1: 
Figura 1: Calçadão da praia de Copacabana

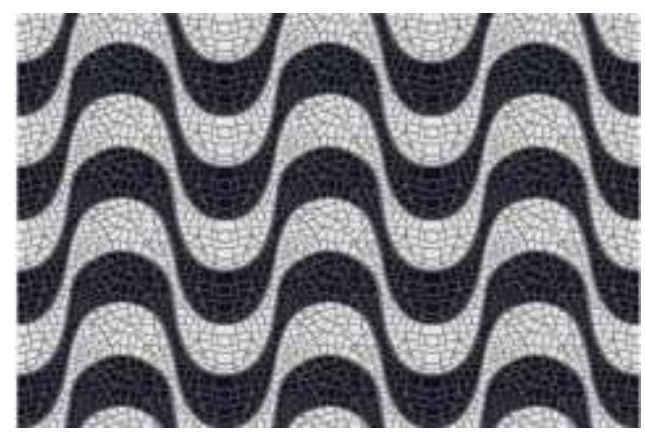

Fonte: <https://www.significados.com.br/mosaico/>. Acesso em 08 de jan. de 2021

Já a Teoria ou Modelo de Van Hiele nos guiou, para este experimento descrito neste artigo, como um instrumento para avaliar a aprendizagem em Geometria dos alunos dentro da construção e posterior análise dos mosaicos. Esta Teoria divide o aprendizado de Geometria em 5 níveis, em que os alunos só podem avançar para o próximo nível depois de completar o anterior ([7], 2007, p. 1). São eles:

- Nível 1 (Reconhecimento ou Visualização) - os alunos usam linguagem informal e tentam ver as diferenças e características das figuras usando seu próprio linguajar.

- Nível 2 (Análise) - os alunos percebem conceitos geométricos presentes nas figuras e são capazes de resolverem problemas usando esses recursos adquiridos neste nível.

- Nível 3 (Abstração ou Classificação) - necessidade, por parte dos estudantes, de definições, classificação das figuras em grupos, etc.

- Nível 4 (Dedução Formal) - os alunos conseguem deduzir propriedades das figuras a partir de outras e inclusive são capazes de provar resultados geométricos.

- Nível 5 (Rigor) - os alunos compreendem demonstrações, axiomas e teoremas. Não é mais necessário, neste nível, o material concreto para análise.

A experiência descrita neste artigo tencionou chegar até o Nível 3 do Modelo de Van Hiele através da construção e manipulação de figuras de mosaicos destinados ao ensino de definições e propriedades de triângulos e quadriláteros para alunos do $7^{\circ}$ ano do ensino fundamental, as quais foram: classificação dos triângulos quanto aos lados e quanto aos ângulos, classificação dos quadriláteros e soma dos ângulos internos de triângulos e quadriláteros.

Na próxima seção, detalharemos os passos da experiência dentro das atividades propostas aos alunos observando os detalhes mais importantes. 


\section{A experiência passo a passo}

Ao se deparar com o nível de conhecimento em Geometria das duas turmas de $7^{\circ}$ ano em que o professor-autor deste trabalho pretendia trabalhar, logo percebeu-se a necessidade de ensinar conhecimentos básicos de Geometria com as duas turmas, pois os alunos não tinham quase ou praticamente nenhuma base de conhecimentos prévios para participarem do referido experimento. Desta forma, o primeiro passo da experiência foi a seguinte atividade de revisão:

Atividade "zero" (dois tempos de 50 minutos) - Foram ensinados, da mesma forma em ambas as duas turmas de $7^{\circ}$ ano escolhidas, os seguintes conceitos geométricos:

- Aula 1 - a reta e seus subconjuntos;

- Aula 2 - ângulos;

- Aula 3 - posições relativas entre duas retas.

Após essa breve revisão, decidiu-se por não realizar um pré-teste nas duas turmas, pois elas haviam tido as mesmas aulas de revisão do conteúdo básico de Geometria para a experiência da referida dissertação descrita neste texto.

Com isso, passou-se para os próximos passos. A turma onde o ensino do conteúdo de triângulos e quadriláteros citados anteriormente foi dado de forma tradicional será denominada, como na dissertação falada, de turma B. A turma onde a experiência de aprendizagem desse mesmo conteúdo foi feita utilizando-se de mosaicos e do Modelo de Van Hiele será denominada por turma A. Com isso, todas as atividades abaixo descritas referem-se à turma experimental $\mathbf{A}$.

\section{Atividade 1 (1 tempo de aula) - Apresentação dos triângulos e quadriláteros}

Nesta atividade, os estudantes começaram, como era de se esperar, pelo Nível 1 do Modelo Van Hiele, o de Reconhecimento. Para isso, eles receberam do professorautor da dissertação relatada neste artigo vários triângulos e quadriláteros coloridos já cortados em papel glacê, como podemos ver na Figura 2. 
Figura 2 - triângulos e quadriláteros distribuídos aos alunos

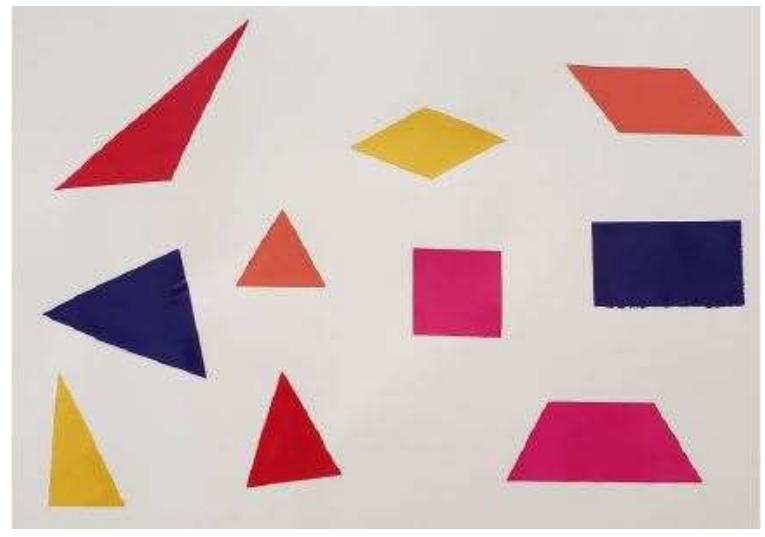

Fonte: [3], 2019, p. 61

As figuras acima foram construídas em papel, usando malhas quadriculadas ou triangulares de forma que facilitasse o encaixe destas peças na construção dos mosaicos. Por exemplo, os triângulos equiláteros, trapézios, losangos e paralelogramos foram construídos numa mesma malha triangular.

Ao manusear as figuras, os alunos logo acharam bastante estranha a forma do triângulo obtusângulo, mas reconheceram imediatamente os quadrados e retângulos. Nessa hora, aproveitou-se para introduzir a palavra "quadrilátero" aos alunos e observar os outros quadriláteros que os alunos não haviam identificado: o losango, o trapézio e o paralelogramo. Com relação aos seus nomes, deixou-se os alunos batizarem as figuras como queriam: "balãozinho" para o losango e "retângulo torto" para o quadrilátero irregular, por exemplo. No caso dos triângulos, todos eles perceberam a característica das figuras por apresentarem 3 lados, mesmo o obtusângulo.

Terminado esse passo, o professor-autor considerou completado o Nível 1 de Reconhecimento do Modelo de Van Hiele e passou para o próximo passo da experiência.

\section{Atividade 2 (1 tempo de aula) - Apresentação dos mosaicos}

Após o professor-autor perguntar aos alunos se eles sabiam o que era um "mosaico" - o que poucos responderam - pediu-se para eles pesquisarem, nos computadores do laboratório de informática da escola, o termo "mosaico". Desta forma, os estudantes puderam ver várias imagens de mosaicos e, como isto é algo bem visual, decidiu-se por não dar uma definição formal para a palavra "mosaico". 
Após esta etapa, foi pedido que os alunos pesquisassem o termo "mosaico geométrico" no buscador do computador. Nesta hora um aluno notou que o piso da sala da sala onde estavam era revestido por um mosaico de ladrilhos regular, que foi explicado posteriormente pelo professor-autor que este tipo de mosaico é aquele formado pela mesma figura que, no caso, eram quadrados. Os alunos não demonstraram muito interesse neste tipo de mosaico de forma geral.

Em seguida, foi pedido para os estudantes pesquisarem no buscador o termo "mosaicos semirregulares". Com isso, o professor-autor explicou aos alunos que este tipo de mosaico é formado por duas ou mais figuras de mesmo formato. Os alunos, que sabiam que iriam ter que construir seus mosaicos na próxima atividade, se sentiram capazes de construí-los, visto que muitas das figuras que apareciam nas telas usavam triângulos e quadrados de mesma medida de lado.

Para os alunos terem uma ideia do que era um mosaico irregular, formado por diversas figuras, o professor-autor os encaminhou à sala de Artes Plásticas do mesmo colégio para visualizaram um mosaico que tinha sido construído no ano anterior por outra turma. Muitos alunos acharam este mosaico esquisito e "feio". Terminada esta etapa, passou-se para a construção dos mosaicos pelos alunos.

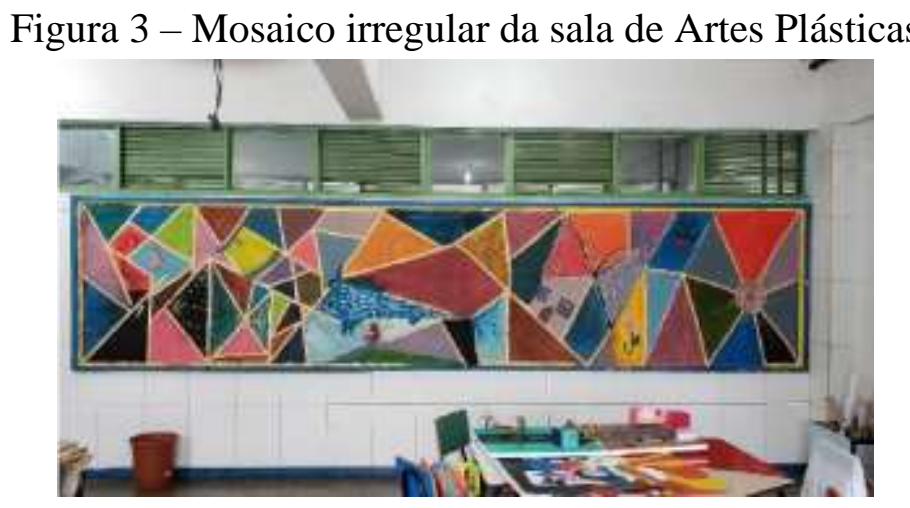

Fonte: [3], 2019, p. 64

\section{Atividade 3 (2 tempos de aula) - Construção dos mosaicos}

O objetivo desta atividade foi que os estudantes conseguissem alcançar o Nível 2 de Análise da Teoria de Van Hiele ao construírem seus mosaicos.

Foi interessante observar que os alunos logo escolheram trabalhar com triângulos equiláteros, pois eles têm lados iguais e deveriam se encaixar melhor na sua montagem. O termo "equilátero" teve que ser explicado aos alunos. 
Após esta observação, o professor-autor cortou as diversas figuras como mostradas na Figura 1. Como os quadrados e os triângulos equiláteros possuíam a mesma medida dos lados, os alunos, em sua maioria, decidiram construir seus mosaicos apenas com essas figuras, como mostrado na Figura 4, em folhas de papel canson A4. Aproveitou-se esse momento para definir para os alunos o conceito de "polígonos regulares".

Vale observar que, durante a produção dos mosaicos pelos alunos, o professorautor só fez observações pontuais a fim de ajudar na construção dos alunos.

Figura 4 - Construção dos mosaicos

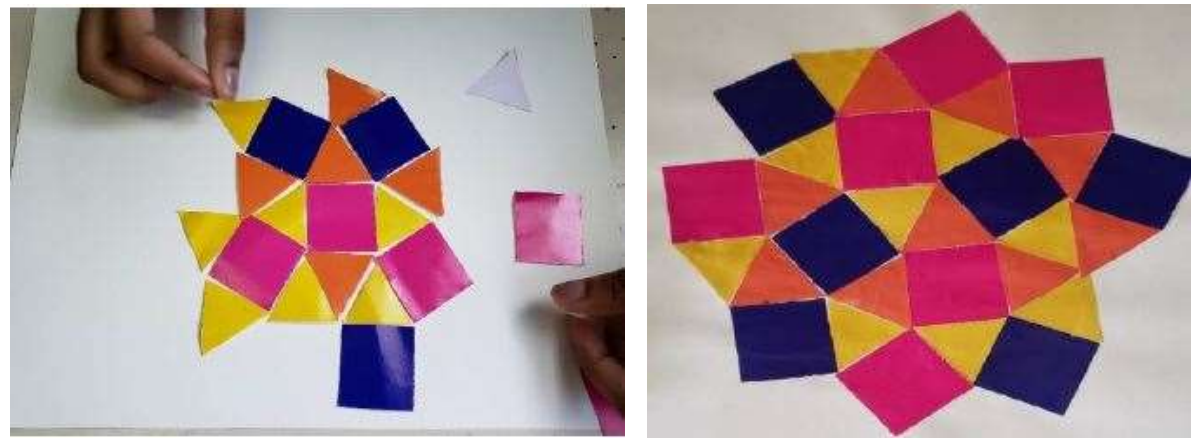

Fonte: [3], 2019, p. 67

\section{Atividade 4 (1 tempo de aula) - Análise dos mosaicos e dos outros triângulos e quadriláteros}

Esta atividade ainda se situa dentro do Nível 2 de Análise do Modelo de Van Hiele. Nela, os alunos da turma A (experimental) usaram os mosaicos que eles construíram na última atividade para que pudesses comparar as figuras e observar suas características.

Os alunos foram divididos em duplas e receberam tanto os mosaicos que construíram quanto as figuras que não utilizaram. Alguns estudantes já conseguiram identificar o losango, pois haviam tentado juntar dois triângulos equiláteros em seus mosaicos. O professor-autor aproveitou este momento para mostrar para os alunos que, assim como o quadrado, essa figura, o losango, também tinha os quatro lados iguais. Comparando com o quadrado, os alunos ficaram entusiasmados com a particularidade daquela figura não ser um quadrado e, embora isto não estivesse previsto nesta parte da atividade, acabou-se por nomear essa ilustre figura por "losango" para os estudantes. Finalmente, com a discussão geral que se formou na turma, eles acabaram percebendo que o quadrado possui todos os ângulos internos de $90^{\circ}$, diferentemente do losango. $\mathrm{O}$ 
mais interessante disso tudo foi que eles chegaram à esta conclusão sozinhos, sem a intervenção do professor-autor.

Em seguida, foi pedido aos alunos que observassem os triângulos, tanto os que foram usados nos mosaicos como os outros. Eles observaram que o triângulo equilátero era o mais adequado para encaixe nos mosaicos por apresentar os lados com mesma medida e que os triângulos retângulos, por terem um ângulo reto, poderia encaixar nos quadrados e retângulos e, sobrepondo essas figuras, acabaram quase por montar novos mosaicos. Infelizmente, os alunos não deram muita importância ao triângulo acutângulo escaleno e ao triângulo obtusângulo, não tecendo assim, nenhum comentário relevante.

Finalmente, com relação aos quadriláteros, os alunos acabaram por se interessar e discutir a forma do paralelogramo comparando-o com o losango, visto que ele também possui pares de lados paralelos. No entanto, assim como antes, os alunos não fizeram qualquer observação sobre os outros quadriláteros, o irregular e o trapézio isósceles, pois estes polígonos não despertaram sua curiosidade. Com isso, o professorautor considerou esta atividade finalizada e prosseguiu para a próxima, a de classificação dos triângulos.

\section{Atividade 5 (2 tempos de aula) - Classificação dos Triângulos}

Neste passo, os alunos chegaram, finalmente, ao Nível 3 de Classificação do Modelo de Van Hiele.

\section{Classificação quanto aos ângulos}

O professor-autor iniciou esta atividade dividindo, novamente, a turma em duplas e distribuindo todos os triângulos recortados. Depois, foi pedido aos alunos que eles dividissem esses triângulos em grupos de acordo com a diferença de seus ângulos internos. Praticamente a turma toda dividiu os triângulos em 2 grupos: um deles contendo os triângulos que eles usaram na construção dos mosaicos e um grupo contendo todos os outros. Os alunos nomearam este segundo grupo como os "excluídos". Nele estavam todos os tipos de triângulos quanto aos lados, mesmo os acutângulos que não eram equiláteros, pois eles não entraram na elaboração dos mosaicos.

Depois desse passo, foi pedido aos alunos que separassem do grupo dos "excluídos" os triângulos que tinham um ângulo reto e, depois, aqueles que possuíam um ângulo maior do que $90^{\circ}$, formando, assim, mais dois grupos de triângulos. Com 
isso, os estudantes acabaram ficando com quatro grupos de triângulos: os equiláteros, os escalenos acutângulos, os retos e os obtusângulos. Foi uma surpresa geral para eles quando o professor-autor informou que só existiam 3 grupos de triângulos na classificação quanto aos seus ângulos. Assim, dois daqueles grupos precisavam ser unidos, mas a turma não foi capaz de identificar quais eram. Com isso, o professor-autor foi à lousa e deu a definição precisa da classificação dos triângulos quanto aos ângulos. Apesar de ter havido um certo estranhamento na junção do grupo dos equiláteros com os escalenos acutângulos, eles acabaram por perceber que, pelos ângulos serem agudos, deveriam sim pertencer ao mesmo grupo desta classificação.

\section{Classificação quanto aos lados}

O professor-autor distribuiu todos os triângulos novamente às duplas formadas da turma A e pediu que os alunos separassem os triângulos de acordo com os lados deles. Como antes, os estudantes separaram as figuras em dois grupos: o dos triângulos equiláteros e o dos outros triângulos. Comentou-se logo em seguida que o grupo dos triângulos equiláteros estava correto, pois tinham todos os lados iguais e foi pedido aos alunos para observarem melhor o outro grupo de triângulos. Com uma rápida observação e o auxílio de uma régua, os alunos puderam ver que alguns dos outros triângulos não equiláteros possuíam dois dos lados iguais. Como foi a única dificuldade que apareceu neste passo da atividade, os alunos separaram os triângulos isósceles dos escalenos e o professor-autor, usando a lousa, deu a devida classificação dos triângulos quanto aos lados.

Para finalizar esta atividade, o professor-autor observou a diferença dessas duas classificações dos triângulos: quanto aos lados ou quanto aos ângulos, o que nem sempre é uma tarefa fácil para o aluno realizar. Findada essa observação, deu-se por encerrada esta atividade.

\section{Atividade 6 (2 tempos de aula) - Classificação dos Quadriláteros}

O objetivo desta atividade, que se encontra dentro do Nível 3 do Modelo de Van Hiele, era que os alunos separassem os quadriláteros em seis grupos de acordo com aqueles que foram fornecidos a eles. No entanto, vale observar que os alunos já estavam familiarizados com as formas dos quadrados e dos retângulos. 
Similarmente ao que foi feito na atividade anterior, distribuiu-se às duplas formadas da turma A todos os quadriláteros recortados no início da experiência e pediuse que os alunos dividissem essas figuras em grupos de acordo com suas características. Prontamente e sem maiores dificuldades, os alunos começaram essa divisão, mas algumas duplas acabaram por ficar com 4 e outras com 5 grupos de quadriláteros, pois algumas delas juntaram os losangos com os paralelogramos e/ou juntaram os trapézios isósceles com os quadriláteros irregulares.

Para começar a separar esses dois grupos, o professor-autor decidiu começar pelo grupo formado por losangos e paralelogramos e pediu para os alunos observarem seus lados. Rapidamente, eles lembraram da outra atividade que o losango possui os quatro lados iguais, enquanto os paralelogramos fornecidos não tinham essa propriedade. Dessa forma, a separação deste grupo em losangos e paralelogramos transcorreu de forma tranquila.

Em relação ao grupo formado pelos trapézios isósceles e os quadriláteros irregulares e sem intervenção do professor-autor, deixou-se que os alunos que haviam percebido a diferença entre eles percorressem a sala de aula comentando que os trapézios possuíam lados "certinhos", expressão que eles usaram para o paralelismo de suas bases, enquanto os outros quadriláteros eram todos "tortos", segundo eles. Com isso, a turma conseguiu, finalmente, separar esse último grupo de maneira correta.

Para a classificação dos quadriláteros, o professor-autor decidiu começar pelo trapézio isósceles desenhando-o na lousa e mostrando que suas bases eram paralelas, prolongando-as para isso e relembrando a aula de revisão sobre retas paralelas. Finalmente, o professor-autor classificou os losangos e os paralelogramos comparandoos com os quadrados e retângulos, pois eles também possuíam pares de lados paralelos. Por último, foi ensinada a classificação de quadrilátero irregular aos alunos.

\section{Atividade 7 (1 tempo de aula) - Soma dos Ângulos Internos}

Desta vez, o professor-autor distribui às duplas formadas os mosaicos que eles haviam montado na outra atividade e pediu para que os alunos observassem que, nos pontos onde 6 triângulos equiláteros se uniam aparecia um ângulo conhecido por eles: o de uma volta. Como eles sabiam que este ângulo possui $360^{\circ}$ e eles usaram seis triângulos, não foi difícil eles chegarem à conclusão, junto com uma observação do professor-autor, de que cada ângulo de cada um dos triângulos deveria ter $60^{\circ} \mathrm{e}$, 
portanto, o triângulo equilátero deveria ter $180^{\circ}$ como soma de seus ângulos internos. Em seguida, distribuiu-se aos alunos os outros triângulos não equiláteros e, com o auxílio de uma tesoura, foi pedido aos estudantes que recortassem os triângulos de forma a poderem juntar os seus ângulos internos. Feito isso, eles prontamente chegaram à conclusão de que todos os ângulos formados eram rasos e que a soma dos ângulos internos de qualquer triângulo é sempre $180^{\circ}$. Para o caso dos quadriláteros, foram primeiramente oferecidos os quadrados e retângulos aos alunos. Pediu-se para observar seus ângulos internos e, como sempre havia 4 ângulos, não houve dúvida para a turma de que a soma dos ângulos internos dessas figuras é sempre de $360^{\circ}$. Perguntou-se aos estudantes se isso era suficiente para garantir que os outros quadriláteros também possuam essa propriedade e logo eles responderam que não. Assim, procedeu-se de forma similar ao recorte dos triângulos para juntar os ângulos dos outros quadriláteros para que os alunos percebessem que, de fato, a soma dos ângulos internos de qualquer quadrilátero corresponde a $360^{\circ}$.

Com esta última atividade, foram propostos exercícios do livro texto e da apostila para que os alunos treinassem os conhecimentos adquiridos. Isto foi feito nas turmas A, experimental, e na B, de controle. Depois, foi feita uma mesma avaliação para as duas turmas para verificar o desempenho dos alunos. Esta avaliação está relatada abaixo junto com algumas observações sobre ela e os resultados obtidos.

\section{A avaliação}

A avaliação aplicada nas turmas A e B (figura 9) conteve questões cujo conteúdo foi aquele somente dado na experiência que estamos descrevendo neste artigo e o professor-autor tentou colocar questões semelhantes às do livro e da apostila dos alunos. Isto foi feito porque as duas turmas tiveram a mesma aula de revisão em preparação para a avaliação. No total, a avaliação contou com seis questões. As questões 1 e 3 eram mais diretas, objetivas e, portanto, os estudantes acabaram apresentando um desempenho melhor nelas. Já as questões 4 e 5, que demandavam um maior raciocínio e algum cálculo (no caso da questão 5), foram aquelas em que os estudantes, de forma geral, sentiram mais dificuldade. Finalmente, as questões 2 e 6 que trataram da soma dos ângulos internos de triângulos e quadriláteros, respectivamente, foi permitida a resolução pelos alunos subtraindo-se os ângulos já conhecidos do total, pois foi dessa maneira que esse tipo de questão foi trabalhada em sala na aula de revisão. Essa forma 
de abordar essas questões deixou os alunos mais à vontade do que usando equações. Em relação ao desempenho das turmas $\mathrm{A}$ e B, foi notório um melhor aproveitamento da turma experimental A em relação ao da turma de controle B. Isto pode ser visto nos gráficos especificados na Figuras 5 e 6.

Figura 5 - Gráfico por Faixa de Aproveitamento da Turma A (experimental)

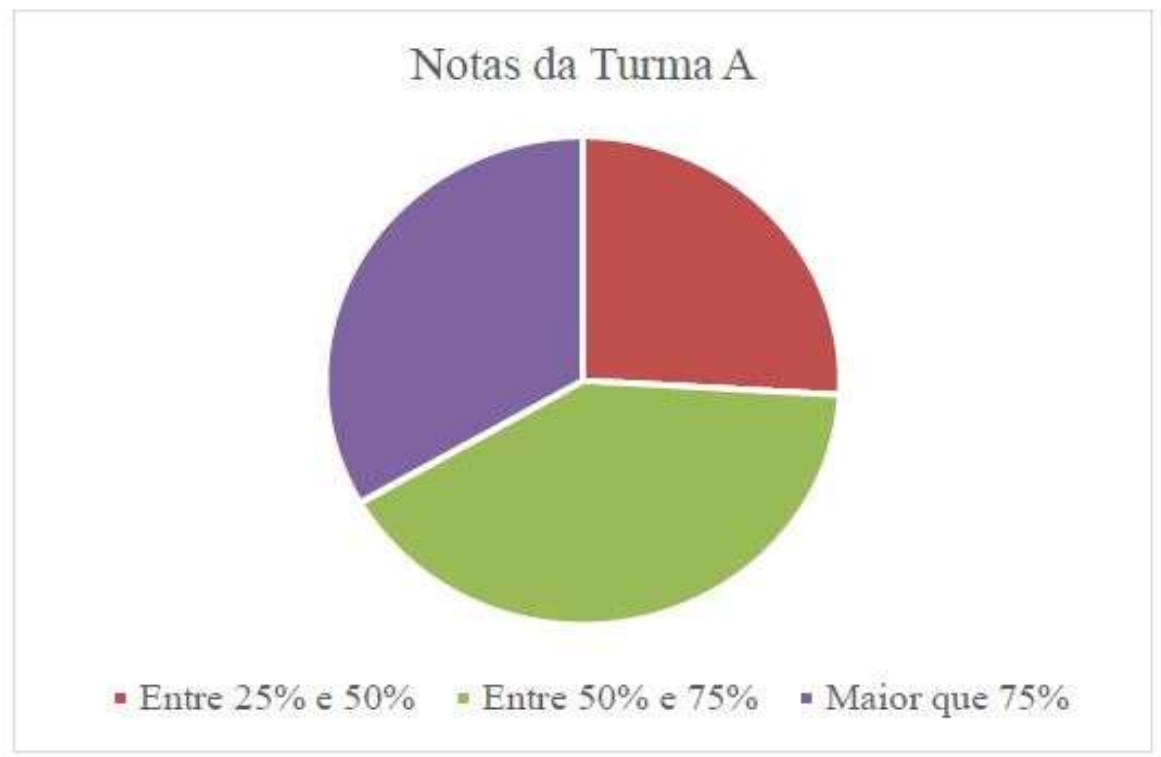

Fonte: [3], 2019, p. 80.

Figura 6 - Gráfico por Faixa de Aproveitamento da Turma B (controle)

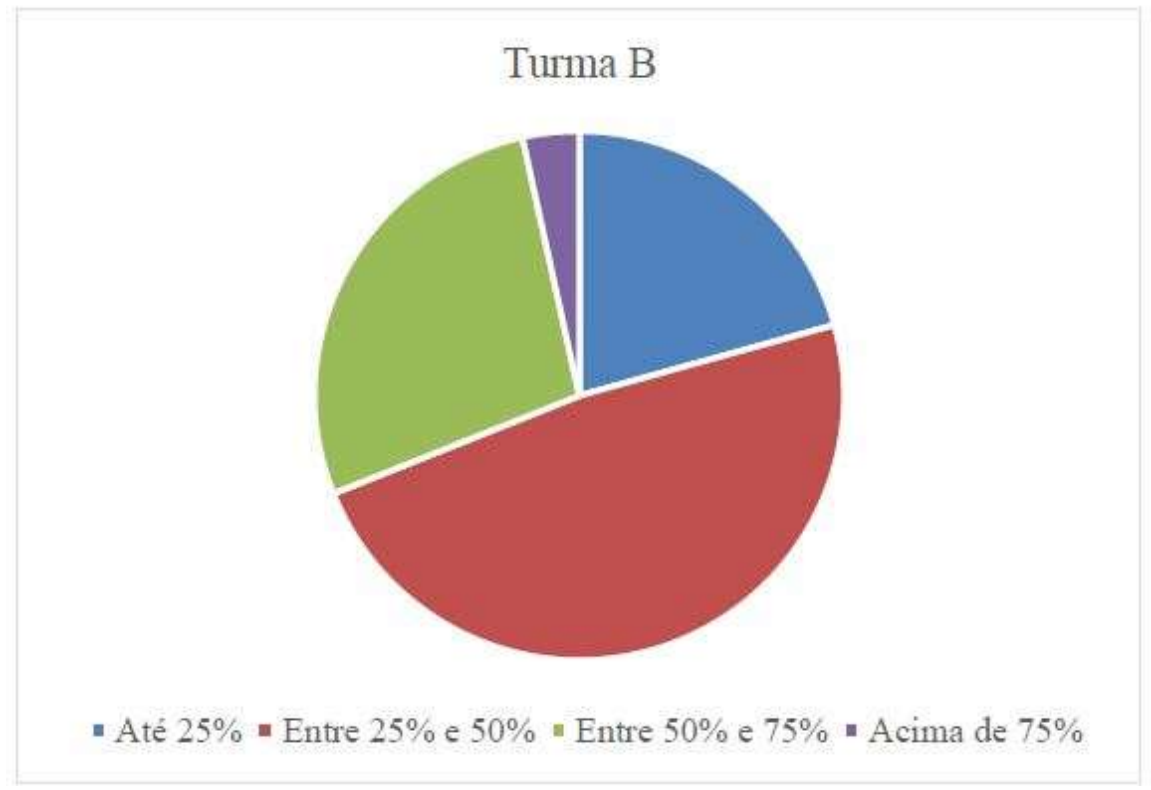

Fonte: [3], 2019, p. 81. 
Figura 7 - Média Aritmética das Turmas

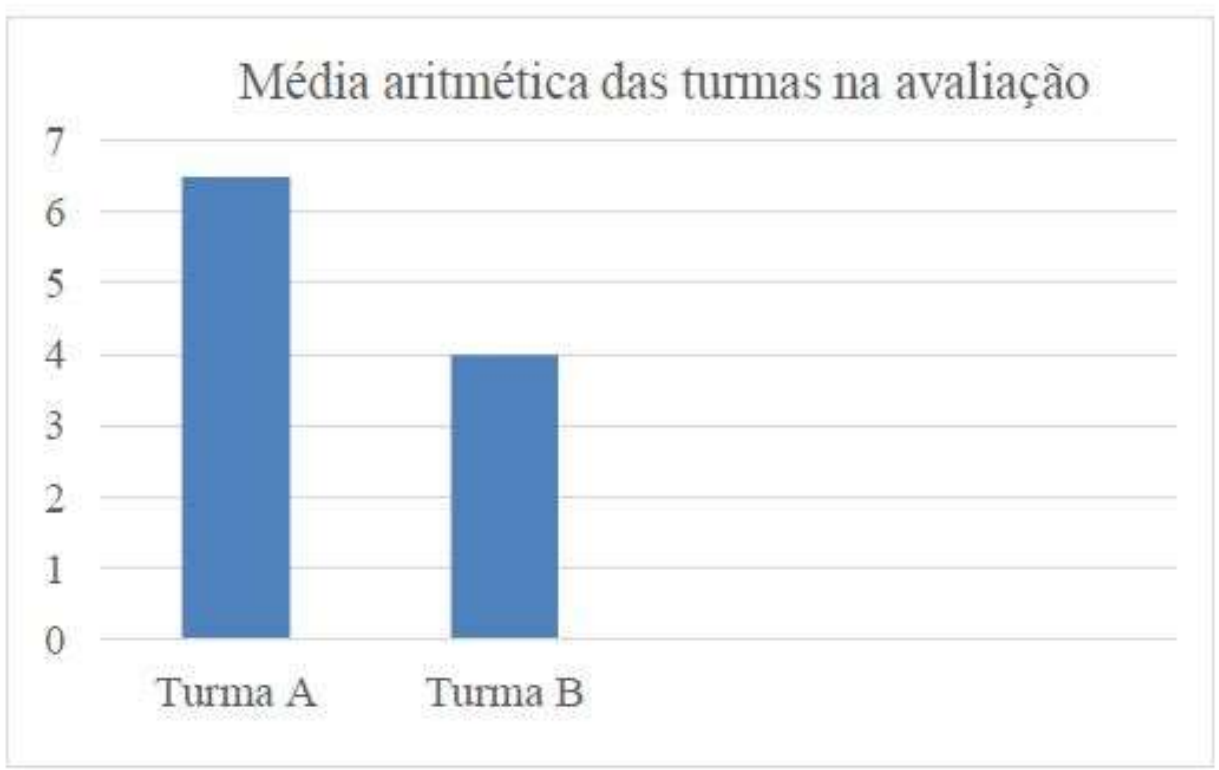

Fonte: [3], 2019, p. 81.

Figura 8 - Comparação Percentual em Relação à Média

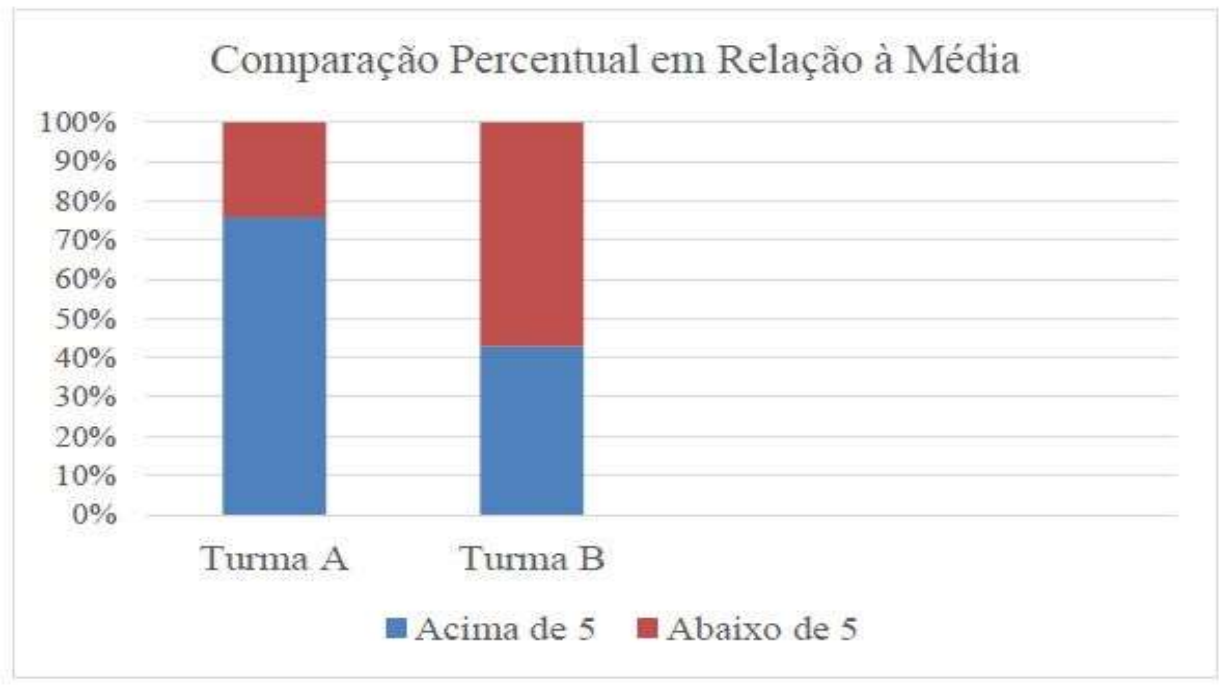

Fonte: [3], 2019, p. 82.

Com os dados ilustrados nas Figuras 5 a 8 e a experiência relatada, procederemos à última parte deste artigo, que trata dos comentários e conclusões acerca deste experimento. 
Figura 9 - Avaliação para duas turmas

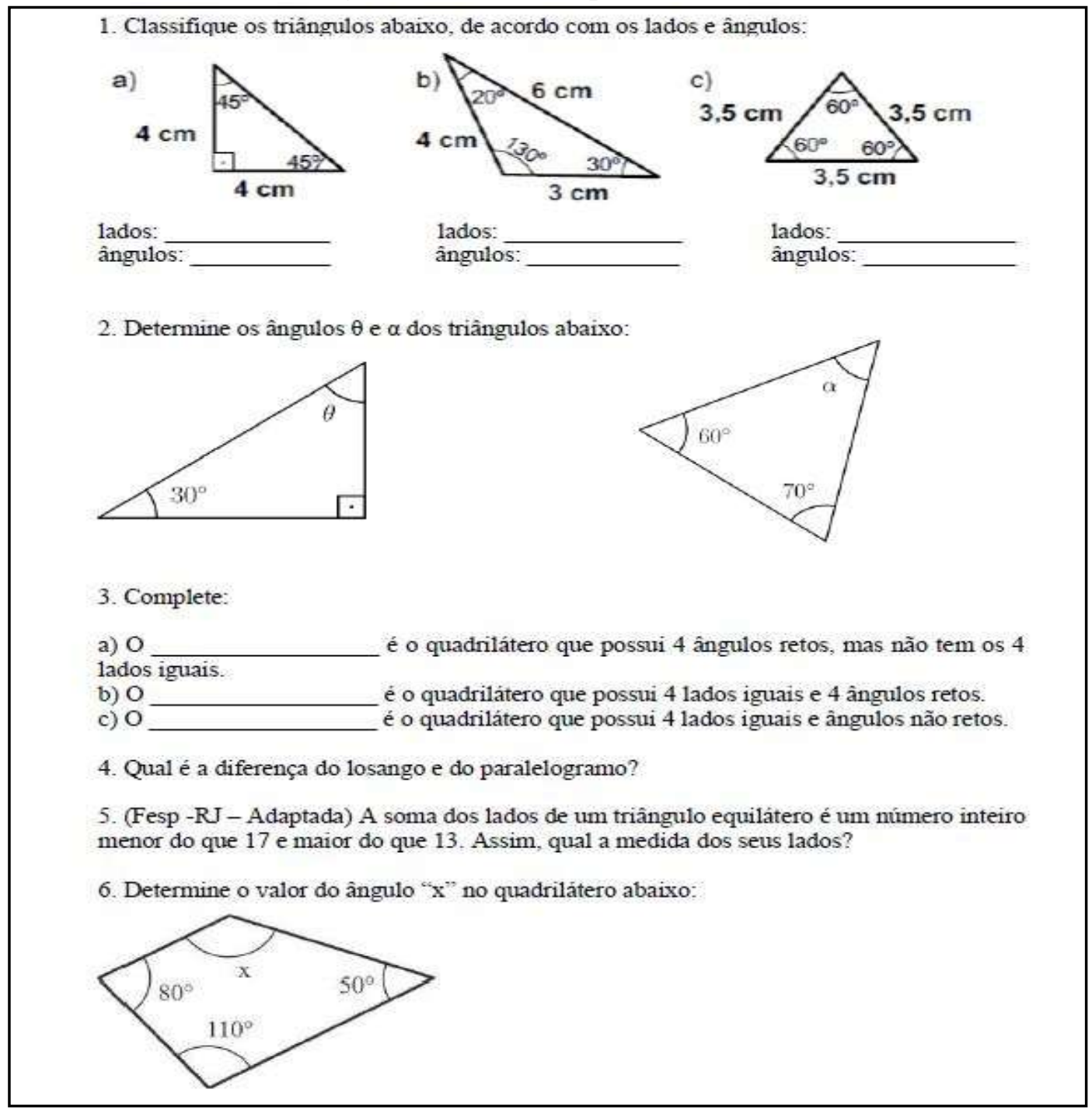

Fonte: [3], 2019, p. 89.

\section{Conclusão}

Além do resultado positivo com o experimento, visto que a turma A apresentou um maior rendimento de forma geral, o que mais chamou a atenção do professor-autor foi a interação, participação e vontade de aprender dos alunos desta turma, coisa rara de se presenciar em aulas de Matemática. Os alunos se sentiram mais à vontade em realizar as atividades propostas e não tinham vergonha ou medo de responder os questionamentos feitos em sala de aula. Até mesmo os alunos que já tinham entendido determinado conteúdo, tomaram uma posição proativa para explicar e ajudar os colegas que ainda apresentavam dificuldades de entendimento. As aulas se tornaram dinâmicas e divertidas, além do conteúdo abordado ser mais bem assimilado nesta turma experimental do que na turma $\mathrm{B}$, de controle, com as aulas tradicionais. 
Como uma observação pertinente, apesar da média aritmética da turma experimental A não ter sido tão alta, já que ficou um pouco acima de 6, isto mostra um melhor desempenho que o da turma B que ficou com 4 e, além disso, é importante destacar que a média da escola onde foi aplicado este experimento, assim como de toda rede municipal de escolas da cidade do Rio de Janeiro, é 5.

Finalmente, pôde-se constatar claramente como a interdisciplinaridade entre Matemática e Artes se apresentou como um ótimo meio de ensinar de forma prazerosa e lúdica conteúdos de Matemática que são considerados difíceis pelos alunos de uma turma de $7^{\circ}$ ano do Ensino Fundamental.

\section{Referências}

[1] ÁVILA, G. O ensino da matemática. Revista do Professor de Matemática, n. 23, p. 5-10, 1983. Disponível em: <http://www.rpm.org.br/cdrpm/23/1.htm>. Acesso em: 08 de jan. 2021.

[2] BRASIL. Base Nacional Comum Curricular. Brasília: MEC, 2017. Disponível em: <http://portal.mec.gov.br/docman/abril-2018-pdf/85121-bncc-ensino-medio/file>. Acesso em: 22 de jan. de 2021.

[3] CAMPOS, A. V. R. Estudo de triângulos e quadriláteros na construção de mosaicos geométricos sob a perspectiva da Teoria de Van Hiele. 2019. $234 \mathrm{f}$. Dissertação (Mestrado em Matemática) - Instituto de Matemática e Estatística, Universidade do Estado do Rio de Janeiro, Rio de Janeiro, 2019.

[4] HAMAZAKI, A. C. O ensino da geometria sob a ótica dos Van Hiele. Universidade Guarulhos. Guarulhos, 2004. Disponível em: <http://www.sbembrasil.org.br/files/viii/pdf/07/2PO13912905851.pdf > . Acesso em 08 de jan. 2021.

[5] LORENZATO, S. Por que não ensinar Geometria? A educação matemática em revista. SBEM, n. 4, p. 3-13, Blumenau, 1995. Disponível em: $<$ http://professoresdematematica.com.br/wa_files/0_20POR_20QUE_20NAO_20ENSI NAR_20GEOMETRIA.pdf >. Acesso em 08 de jan. 2021.

[6] PAVANELLO, R. M. O abandono do ensino da geometria no Brasil: causas e consequências. Revista Zetetiké, Ano I, n.1, p. 7-17, Campinas, 1993. Disponível em: <https://periodicos.sbu.unicamp.br/ojs/index.php/zetetike/article/view/8646822/13724>. Acesso em 08 de jan. 2021.

[7] SILVA, L.; CANDIDO, C. C. Modelo de aprendizagem de geometria do casal Van Hiele. IME-USP, São Paulo, 2007. Disponível em:

$<$ https://edisciplinas.usp.br/pluginfile.php/2404060/mod_resource/content/1/Silva\%20\% 
20Candido\%20\%20Modelo\%20de\%20Aprendizagem\%20da\%20Geometria\%20do\%20 Casal\%20Van\%20Hiele.pdf>. Acesso em 09 de jan. 2021. 